\title{
Experimental Study on Uniaxial Compression of Bamboo Poles with Different Reinforcements
}

\author{
Xinmiao Meng ${ }^{1, *}$, Yuyang $\mathrm{Cao}^{1}$, Han $\mathrm{Sun}^{1}$ and Peng Feng ${ }^{2}$ \\ ${ }^{1}$ Department of Civil Engineering, Beijing Forestry University, Beijing, China. \\ 2 Department of Civil Engineering, Tsinghua University, Beijing, China.
}

\begin{abstract}
The natural round bamboo is a kind of ecological building material with many excellent physical and mechanical characteristics, such as fast growth, high strength and good environmental performance. However, the natural round bamboos were barely used for its worse durability and easiness to crack compared other bamboo productions after secondary operation. In order to improve the safety and durability of the round bamboo structure, the axial compression test of the GFRP (glass fiber-reinforced polymer) and/or mortar reinforcing cracked bamboo was conducted. The $20 \mathrm{~cm}$ tall round bamboo column specimens were divided into five categories: the first without cracks and reinforcement, the second with cracks but without reinforcement, the third with cracks and full GFRP reinforcement, the forth with cracks and fulfil of cement motrar, and the last with cracks and reinforced using both GFRP and cement mortar. The bearing capacity and the failure modes were observed and studied. It was found that the composite reinforcement of GFRP and mortar could significantly increase the bearing capacity of the cracked round bamboos, and avoid brittle failure through improving the ductility of the specimens.
\end{abstract}

\section{Introduction}

Bamboo is a kind of ecological building material for its physical and mechanical characteristics, such as fast growth, light weight, high strength, and good environmental performance [1-4]. However, it was barely used for its worse durability and easiness to crack compared other bamboo productions after secondary operation [5]. Then it is very important to reduce the negative effects of cracks to improve the safety and durability of the round bamboo structure.

Fiber-reinforced polymer (FRP) has been widely applied to improve the bearing capacity and ductility of concrete and metallic structures due to their high strengths, low weights, anti-corrosion capability and easy forming characteristics. This method is typically used to reinforce columns via wrapping to provide confinement. Additionally, cement mortar has also been widely used to prevent the local bulking of thin-wall hollow structures. Awaludin et al. [6] used different fibers to reinforce the bolted joints, The results showed that a significant increase of joint slip modulus and load carrying capacity was found in the joints reinforced with FRP. The wrapping effect caused by FRP sheets successfully postpones the bamboo splitting failure. However, in the case of joints reinforced with natural fiber ijuk, this increase is negligible. Huang [7] studied the mechanical properties of bamboo reinforced with CFRP or wire in different ways, using experimental research analysis method, to find out the better strengthening methods, which can provide reference for engineering applications.

In this study, natural round bamboo were reinforced using different methods, including fulfilling cement mortar, and/or wrapped with GFRP sheets. The specimens were tested to analyze the influence of the reinforcements on the failure mode, load capacity and ductility of the round bamboo elements.

\section{Experimental Program}

\subsection{Specimens}

The bamboo was cut from Xianning, Hubei Province. The bamboo was about 15 meters in length. The moisture content of the bamboo pole is about $15 \% .15$ bamboo nodes were cut from two natural bamboos. The specimen was named as $x-y-z$, where $x, y$ and $z$ represented the group of the bamboo, the position of the bamboo node, and the reinforcement method. The group of bamboo was called A, B, C. The position was designated from the bottom (B) to the middle (M) and to the top $(\mathrm{T})$. The reinforcement method was five groups: divided into unreinforced (U), unreinforced but cracked (UC), reinforced with GFRP (G), reinforced with cement mortar (M) and reinforced with both GFRP and mortar (GM). The details of the specimens was shown in Table 1.

The glass fiber sheets used in the tests were HITEXG430S, which were produced by Nanjing Hitech

\footnotetext{
* Corresponding author: mengxinmiao@bifu.edu.cn
} 
Composites Co., Ltd, Jiangsu, China. The resin used in the study was Lica100 structural adhesive and was produced by the same company. In this study, a single layer of GFRP sheet was used, and the fiber mass fraction was approximately $35 \%$. The compressive strength of the cement mortar was $f_{\mathrm{u}}=21.1 \mathrm{MPa}$.

Table 1. The details of specimens

\begin{tabular}{|c|c|c|c|}
\hline Specimens & Area $\left(\mathrm{mm}^{2}\right)$ & Cracks & Reinforcement \\
\hline A1-B-U & 1967 & None & None \\
\hline A2-M-U & 1855 & None & None \\
\hline A3-T-U & 1790 & None & None \\
\hline B1-B-UC & 2987 & Severe & None \\
\hline B2-M-UC & 2452 & Slight & None \\
\hline B3-T-UC & 1498 & Slight & None \\
\hline C1-B-G & 2730 & Severe & GFRP \\
\hline C2-M-G & 2298 & Slight & GFRP \\
\hline C3-T-G & 1397 & Slight & GFRP \\
\hline D1-B-M & 2356.34 & None & Mortar \\
\hline D2-M-M & 1573.27 & None & Mortar \\
\hline D3-T-M & 1275.99 & None & Mortar \\
\hline E1-B-GM & 2149.72 & Severe & GFRP+Mortar \\
\hline E2-M-GM & 1579.81 & Severe & GFRP+Mortar \\
\hline E3-T-GM & 1007.82 & Severe & GFRP+Mortar \\
\hline
\end{tabular}

\subsection{Experimental setup and instrumentations}

The typical test setups for the bamboo columns and beams are shown in Figure 1. Before loading to failure, each column was pre-loaded to a relatively small stress, and its position was correspondingly adjusted after each preloading based on the differences between the readings from the displacement transducers located on opposite sides of the specimens to minimize the loading eccentricity on each specimen. The loading was controlled by the displacement magnitude, and the loading rate was approximately $1 \mathrm{~mm} / \mathrm{min}$.

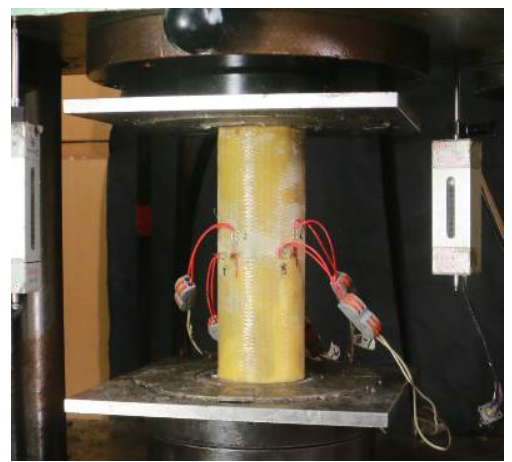

Fig. 1. Experimental setup and instruments

\section{Experimental Program}

For the specimens in Group A and B, at the beginning of the loading, the bamboo columns were slowly compressed, and a slight sound might occur. At the same time, the curve rose linearly. Then the curve began to soften slowly. When the load increased to the peak load, the cracks developed rapidly, the lower part of the bamboo node gradually expanded, and the bearing capacity decreased rapidly, accompanied by a relatively loud sound. Then the crack developed and the bearing capacity of the bamboo columns continued to weaken. The cracks of the specimens in Group B mainly occurred at the original cracks as Figure 2 shown.

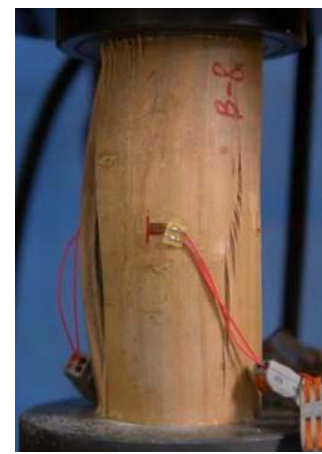

(a) Group A

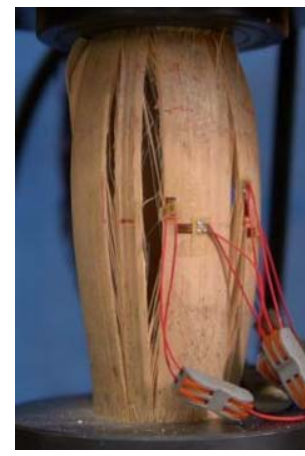

(b) Group B
Fig. 2. Compressive failure of specimens Group A and B.

For the specimens in Group C, with the confinement of GFRP, the development of cracking was restrained. However, the inward buckling deformation was clearly observed. The capacity was held on a high level until the buckling fully developed.

For the specimens in Group D, the infilled cement mortar was already compressed to failure even the cracks not showing on the surface, so the mortar was a bad effect to the outer bamboo wall to accelerate its buckling outward.

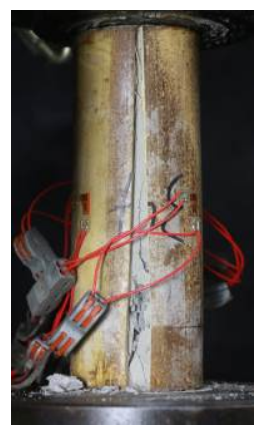

(a) Group C

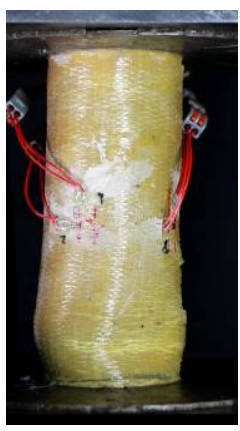

(b) Group D

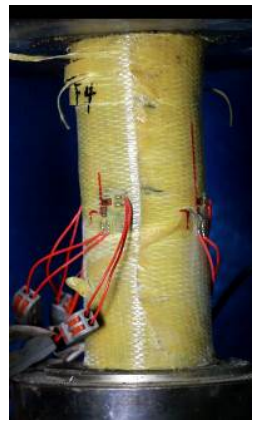

(c) Group E
Fig. 3. Compressive failure of specimens Group C, D and E.

For the specimens in Group E, The observations of reinforced column specimens during their early loading processes were similar to Group C. The mechanical behaviors of these specimens, including compression and lateral deformation, were not significant at the beginning of the loading process. When the stress increased, the color of the FRP material at the end of the columns first changed to white, and then, transverse cracks formed. However, the white zones did not evenly spread to the middle of the specimen thereafter. As the yielding load was approached, the fibers at the end of the specimens started to rupture, and the columns gradually 
started to densify. When the specimens reached their maximum load, failure occurred in one or two primary fracture zones, where compression rapidly progressed, fractures rapidly developed, and the load capacity of the specimen sharply decreased.

\section{Results and discussion}

\subsection{Capacity and deformation}

The results of the axial compressive strength of the bamboo columns are shown in the Table 2 below.

Table 2. The experimental results of specimens

\begin{tabular}{|c|c|c|c|}
\hline Specimens & $\begin{array}{c}\text { Area } \\
\mathbf{( m m}^{\mathbf{2}} \mathbf{)}\end{array}$ & $\begin{array}{c}\text { Peak load } \\
\mathbf{( k N )}\end{array}$ & $\begin{array}{c}\text { Maximum } \\
\text { stress }(\mathbf{M P a})\end{array}$ \\
\hline A1-B-U & 1967 & 109.89 & 55.9 \\
\hline A2-M-U & 1855 & 107.24 & 57.8 \\
\hline A3-T-U & 1790 & 103.68 & 57.9 \\
\hline B1-B-UC & 2987 & 122.97 & 41.1 \\
\hline B2-M-UC & 2452 & 123.74 & 50.5 \\
\hline B3-T-UC & 1498 & 90.73 & 60.6 \\
\hline C1-B-G & 2730 & 152.67 & 55.9 \\
\hline C2-M-G & 2298 & 137.24 & 59.7 \\
\hline C3-T-G & 1397 & 106.54 & 76.3 \\
\hline D1-B-M & 2356.34 & 124.48 & 52.8 \\
\hline D2-M-M & 1573.27 & 99.28 & 55.0 \\
\hline D3-T-M & 1275.99 & 64.72 & 63.1 \\
\hline E1-B-GM & 2149.72 & 260.31 & 121.1 \\
\hline E2-M-GM & 1579.81 & 212.15 & 134.3 \\
\hline E3-T-GM & 1007.82 & 114.68 & 113.8 \\
\hline
\end{tabular}

\subsection{The influence of original cracks}

It was clearly seen that the Group B had lower stress than that of Group A, which showed the original cracks decreased the capacity of the specimens. Additionally, it was also observed that the development of the cracks for Group B was along the original cracks, and the cracks were less uniform on the surface when reaching the maximum load.

The typical load-displacement curve was shown in Figure 4, which indicated that the original cracks decreased the deformation performance, and increased the brittle characteristic of the final failure.

\subsection{The comparison of reinforcements}

The cement mortar could prevent the inward local buckling and provide a bearing part for the column theoretically. However, the mortar fulfilling the bamboo polo didn't improve the mechanical behaviour at all as Figure 5 showed. The reason was that the mortar had already failed and dilated before the bamboo cracking, which would accelerate the development of cracks and make the distribution of cracks uneven.

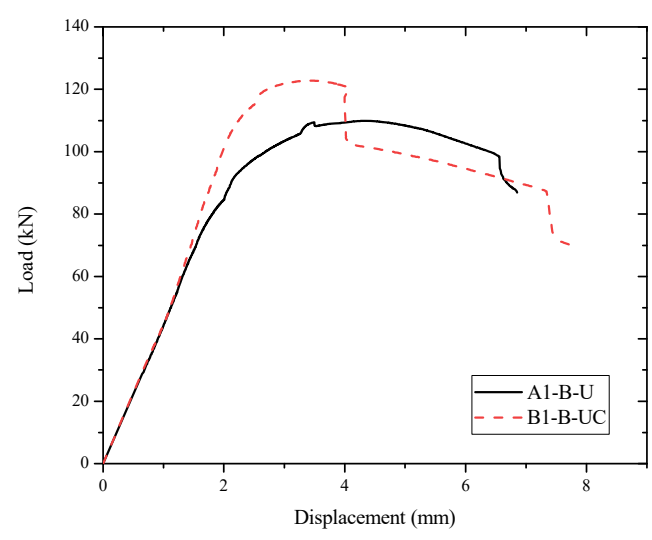

Fig.4. Load-displacement curves of Group A and B

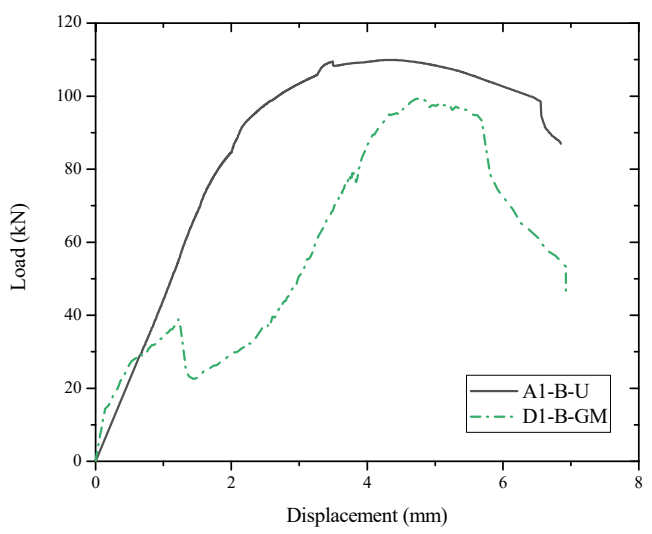

Fig.5. Load-displacement curves of Group A and D

The GFRP reinforcement could provide the confinement to the column. It was shown in Figure 6 that the wrapping method changed the failure modes from outward split to inward deformation, and improved the peak loads and markedly improved compression deformation. However, the inward local buckling could not be avoided.

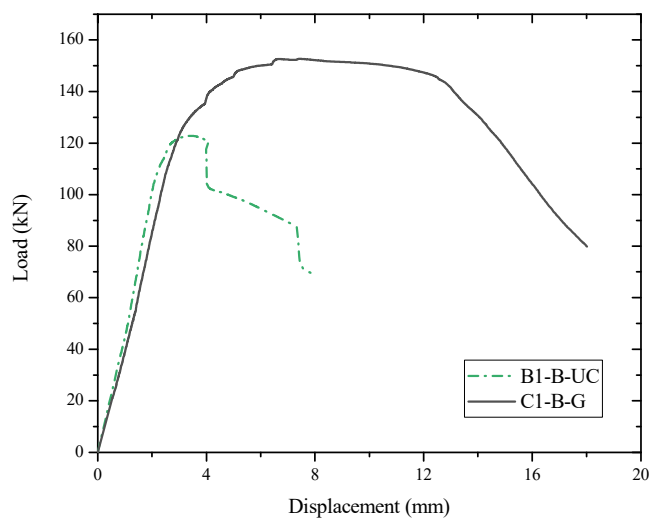

Fig.6. Load-displacement curves of Group B and C

In this case, the composite of GFRP and mortar was reasonable to improve the mechanical behaviour. The GFRP provided the confinement and the mortar prevent the inward buckling. It was demonstrated in Figure 7 that the composite had the best effect. 


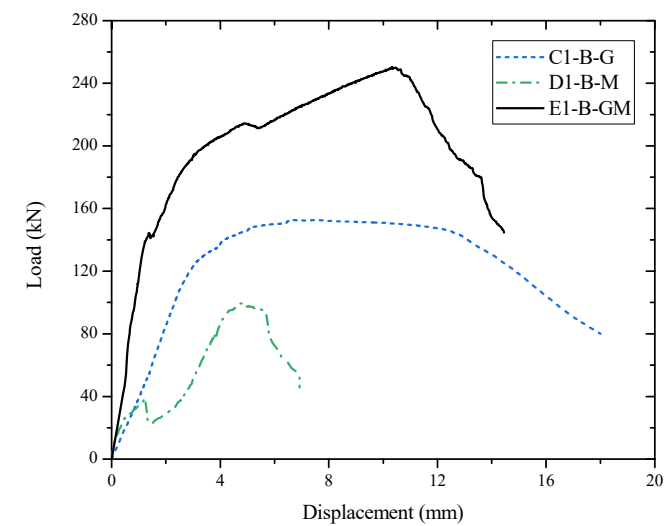

Fig.7. Load-displacement curves of Group C, D and E

\section{Conclusion}

In this paper, the axial compression test of the GFRP and/or reinforcing cracked bamboo was conducted. The bearing capacity and the failure modes were observed and studied. The main research conclusions and achievements includes:

(1) The wrapping method changed the failure modes from outward split to inward deformation, and improved the peak loads and markedly improved compression deformation.

(2) The composite reinforced method showed better mechanical behavior. The confinement effect of FRP sheets wasn't fully used if without fulfilling cement mortar.

(3) The reinforced cracked round pole bamboos might promote the development and application bamboos in constructions and buildings.

\section{Acknowledgments}

The authors acknowledge funding supported by Major Science and Technology Program for Water Pollution Control and Treatment (No.2017ZX07102-001), and supported by the Fundamental Research Funds for the Central Universities of China (No. BLX201706), and supported by the National Natural Science Foundation of China (No. 51278276 and No. 51522807).

\section{References}

[1] Tan T, Rahbar N, Allameh S M, et al. Mechanical properties of functionally graded hierarchical bamboo structures. Acta Biomaterialia, 2011, 7(10): 3796-3803.

[2] Habibi M K, Samaei A T, Gheshlaghi B, et al. Asymmetric flexural behavior from bamboo's functionally graded hierarchical structure: underlying mechanisms. Acta biomaterialia, 2015, 16: 178-186.

[3] Nogata F, Takahashi H. Intelligent functionally graded material: bamboo. Composites Engineering, 1995, 5(7): 743-751.

[4] Amada S, Ichikawa Y, Munekata T, et al. Fiber texture and mechanical graded structure of bamboo. Composites Part B: Engineering, 1997, 28(1-2): 13-20.
[5] Yu D, Tan H, Ruan Y. A future bamboo-structure residential building prototype in China: Life cycle assessment of energy use and carbon emission. Energy and Buildings, 2011, 43(10): 2638-2646.

[6] Awaludin A, Andriani V. Bolted bamboo joints reinforced with fibers. Procedia Engineering, 2014, 95:15-21.

[7] Huang G. The experimental research and analysis on the mechanical properties of reinforced bamboo. Shanghai Jiao Tong University, 2015. 